\title{
Laparoscopic surgery during the COVID-19 pandemic: detection of SARS-COV-2 in abdominal tissues, fluids, and surgical smoke
}

\author{
Isaac Cheruiyot ${ }^{1}$ (D) Prabjot Sehmi $^{1} \cdot$ Brian Ngure $^{1} \cdot$ Musa Misiani $^{1} \cdot$ Paul Karau $^{2} \cdot$ Beda Olabu $^{1}$. \\ Brandon Michael Henry ${ }^{3} \cdot$ Giuseppe Lippi $^{4} \cdot$ Roberto Cirocchi $^{5} \cdot$ Julius Ogeng'o ${ }^{1}$
}

Received: 4 September 2020 / Accepted: 28 February 2021 / Published online: 6 March 2021

(C) The Author(s), under exclusive licence to Springer-Verlag GmbH Germany, part of Springer Nature 2021

\begin{abstract}
Background There are still concerns over the safety of laparoscopic surgery in coronavirus disease 2019 (COVID-19) patients due to the potential risk of viral transmission through surgical smoke/laparoscopic pneumoperitoneum.

Methods We performed a systematic review of currently available literature to determine the presence of severe acute respiratory syndrome coronavirus 2 (SARS-COV-2) in abdominal tissues or fluids and in surgical smoke.

Results A total of 19 studies (15 case reports and 4 case series) comprising 29 COVID-19 patients were included. The viral RNA was positively identified in 11 patients (37.9\%). The samples that tested positive include the peritoneal fluid, bile, ascitic fluid, peritoneal dialysate, duodenal wall, and appendix. Similar samples, together with the omentum and abdominal subcutaneous fat, tested negative in the other patients. Only one study investigated SARS-COV-2 RNA in surgical smoke generated during laparoscopy, reporting negative findings.

Conclusions There are conflicting results regarding the presence of SARS-COV-2 in abdominal tissues and fluids. No currently available evidence supports the hypothesis that SARS-COV-2 can be aerosolized and transmitted through surgical smoke. Larger studies are urgently needed to corroborate these findings.
\end{abstract}

Keywords COVID-19 · Surgery $\cdot$ Surgical smoke

\section{Introduction}

The safety of laparoscopic surgery (LS) in the currently ongoing coronavirus disease 2019 (COVID-19) pandemic is still unclear due to concerns of possible disease transmission via surgical smoke/laparoscopic pneumoperitoneum [1-3]. The expression of angiotensin-converting enzyme 2

Isaac Cheruiyot

isaacbmn@outlook.com

1 School of Medicine, College of Health Sciences, University of Nairobi, Nairobi, Kenya

2 Department of Internal Medicine, School of Medicine, Kenya Methodist University, Meru, Kenya

3 Cardiac Intensive Care Unit, The Heart Institute, Cincinnati Children's Hospital Medical Center, Cincinnati, OH, USA

4 Section of Clinical Biochemistry, Department of Neuroscience, Biomedicine and Movement, University of Verona, Verona, Italy

5 Department of Surgical Science, University of Perugia, Piazza dell'Universitá, 1, 06123 Perugia, PG, Italy
(ACE2) in the gastrointestinal tract [4] and prolonged fecal shedding of severe acute respiratory syndrome coronavirus 2 (SARS-COV-2) in COVID-19 patients [5] suggest that the gastrointestinal tract may serve as a site of viral entry and replication. Moreover, gastrointestinal symptoms are common in COVID-19, with abdominal pain and nausea/ vomiting reported to be associated with increased odds of progression to severe disease [6].

It has been theorized that the use of energy devices such as monopolar and bipolar electrocautery during LS may result in the aerosolization of SARS-COV-2 $[2,7,8]$. The relatively stagnant heated volume of gas created by laparoscopic pneumoperitoneum may allow concentration of the virus [9], to which the surgeon and operating room staff may be exposed during port insertion or removal, exchange of laparoscopic instruments, specimen retrieval, or evacuation of pneumoperitoneum at the end of the procedure. This theory is supported by previous studies in which viruses such as hepatitis B virus (HBV) [10], human papillomavirus virus (HPV) [11], and human immunodeficiency virus 1 (HIV-1) [12] could be detected in vapors created by power surgical instruments. 
The aerosolization of SARS-COV-2 would require the virus to be present intraperitoneally in the first place. Therefore, we performed a systematic review of currently available literature to determine if SARS-COV-2 is present in abdominal fluids or tissues and in surgical smoke generated during abdominal surgery on COVID-19 patients.

\section{Methods}

\section{Study protocol and registration}

This systematic review was conducted in conformity with the preferred reporting items for systematic reviews and metaanalyses (PRISMA) guidelines [13] (Supplementary material 1). The protocol for this study was registered on PROSPERO, an international prospective database for systematic reviews (Registration no. CRD42020200078).

\section{Literature search strategy}

A comprehensive and systematic search of literature from inception to 11 February 2021 was conducted on the electronic databases MEDLINE (PubMed interface), Hinari (Health InterNetwork Access to Research Initiative), and China National Knowledge Infrastructure (CNKI) to identify the studies eligible for inclusion. The electronic search was carried out using the strategy as follows: (SARS-COV-2) AND ((((abdominal tissues) OR (peritoneal fluids)) OR (bile)) OR (surgical smoke)). No language restriction was applied. When the articles were published by the same study group and there was an overlap of the search period, only the most recent article was included to avoid duplication of data. The PubMed function "related articles" was used to extend the search. We also searched major surgical and infectious disease journals reporting articles about COVID-19 infection to look for additional studies. We then performed hand-search of the bibliography of included studies, to detect other potentially eligible investigations.

\section{Eligibility criteria}

Search results were screened by title and abstract, with those of potential relevance evaluated by full text. Studies were deemed eligible for inclusion if they fulfilled the following criteria: (1) clinical studies on patients with a confirmed diagnosis of COVID-19 and (2) investigated the presence of SARS-COV-2 in patients' abdominal fluids (peritoneal fluid/ bile/ascitic fluid/peritoneal dialysate) or abdominal tissue (bowel wall, adipose tissue). Exclusion criteria were the following: (1) studies with incomplete or unclear data and (2) studies reporting SARS-COV-2 tests on samples other than the ones outlined in the inclusion criteria.

\section{Data extraction and quality assessment}

Data extraction was conducted by two independent reviewers (I.C, P.S). For each study, the following information was extracted: the surname of the first author and the year of publication, the geographical region where the study was performed, the type of study, age and sex composition of the patients, type of surgical procedure, nature of the procedure (elective or emergency), types of samples tested, type of test performed, and the outcome of the test. Any variances were resolved by a consensus. Quality assessment and analysis of risk of bias of all selected full-text articles were performed using the methodological index for non-randomized studies (MINORS) tool.

\section{Outcomes of interest}

The primary outcome of interest was the presence of SARS-COV-2 RNA in abdominal fluids and tissues. The secondary outcome was the presence of SARS-COV-2 RNA in surgical smoke generated during abdominal surgery.

\section{Results}

\section{Study identification}

The initial search produced 976 potentially relevant articles. Following the removal of duplicates and primary screening, 86 articles were assessed by full text for eligibility. Of these, 67 were excluded because the primary and secondary outcome of the study did not match that of this review. Thus, a total of 19 articles were included in this systematic review (Fig. 1 and Table 1).

\section{Characteristics of the included studies and quality assessment}

A total of 19 studies ( $n=29$ COVID-19 patients) were included [14-32]. These patients were diagnosed with COVID-19 on the basis of positive reverse transcriptase-polymerase chain reaction (RT-PCR) in oropharyngeal and/or nasopharyngeal swabs in 17 studies. The other two utilized anti-SARS-COV-2 immunoglobulin $\mathrm{G}$ (IgG) assay [29] and chest CT scan [30]. Fifteen were case reports, while 4 were case series. Of the included studies, 11 were from Europe, 5 from Asia, 1 from the Middle East, and 2 from the Americas. The essential characteristics of the included studies are outlined in Table 1. A summary of the MINORS assessment for the included studies is provided in Supplementary material 2. 
Fig. 1 Flow of studies through the meta-analysis

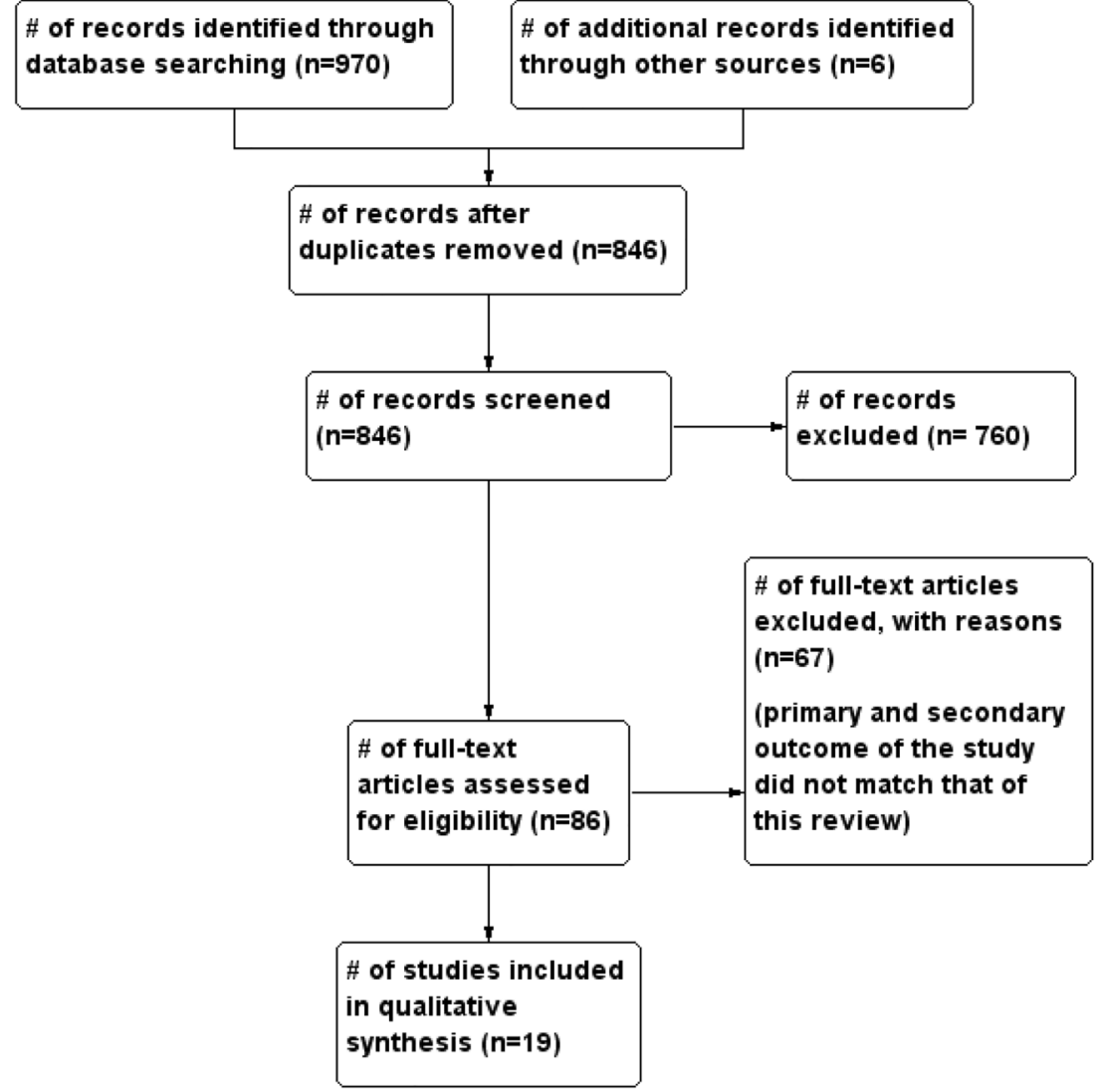

\section{Presence of SARS-COV-2 in abdominal fluids and tis- sues of COVID-19 patients}

The abdominal fluids and tissues tested across the 19 studies included the peritoneal fluid $[14,20,22,24,25,28]$, peritoneal dialysate $[21,31,32]$, ascitic fluid $[17,19,26]$, bile $[15$, 17, 18, 27, 30], small bowel and appendix [16, 29], liver and gallbladder $[16,17]$, and visceral fat (omentum and abdominal subcutaneous tissues [16] (Table 2). All studies tested for SARS-COV-2 presence using reverse transcriptasepolymerase chain reaction (RT-PCR), but none assessed the presence of viable particle with cytopathic studies. Overall, the positive identification of SARS-COV-2 RNA was reported in 11 out of the 29 patients $(37.9 \%)$ included in this review. The time from diagnosis of COVID-19 to testing of various abdominal tissues/samples was reported in 12 studies, and it ranged from 0 to 63 days (Table 1).

The largest study was a case series of 5 surgical patients (bowel resection, appendectomy, rectosigmoid resection, and drainage of hemoperitoneum) from Strasbourg, France [14]. Peritoneal fluid samples were obtained both at the beginning and at the end of the operation in three patients and only at the beginning in two patients. The fluid samples tested negative for SARS-COV-2 in all patients [14]. In another case series of 4 surgical patients from Tehran, Iran, SARS-COV-2 RNA was detected in the duodenal wall of the patient with perforated peptic ulcer. The peritoneal fluid of this patient was however negative for the virus, as were multiple samples (small bowel wall, appendix, gallbladder, bile, liver, visceral fat (omentum), abdominal subcutaneous tissue) from the other 3 patients [16]. Similarly, Scutari and colleagues [27] in their study successfully identified SARS-COV-2 in two patients with acute cholecystitis.

The rest of the studies were single-patient case reports, with 8 reporting cases of successful detection of SARS-COV-2 in abdominal samples. Han and colleagues [18] reported a case of a 59-year-old patient with severe COVID-19 requiring mechanical ventilation and a history of liver transplantation. The patient developed biliary obstruction during admission, treated with endoscopic retrograde cholangiopancreatography (ERCP) and nasobiliary drainage. Bile samples from this patient tested using real-time fluorescent RT-PCR were positive for SARS-COV-2 RNA [18]. Culver et al. [19] described the case of a 71-year-old patient admitted to the intensive care unit due to severe upper gastrointestinal bleed requiring endoscopic treatment. After an initial recovery phase, the patient subsequently developed severe respiratory distress and rapidly deteriorated. Ultrasound performed during diagnostic imaging for COVID-19 revealed large ascites, which upon drainage tested positive for SARS-COV-2 RNA [19]. The third study with positive RNA detection was published by Coccolini and colleagues [22], who detected SARS-COV-2 in peritoneal 


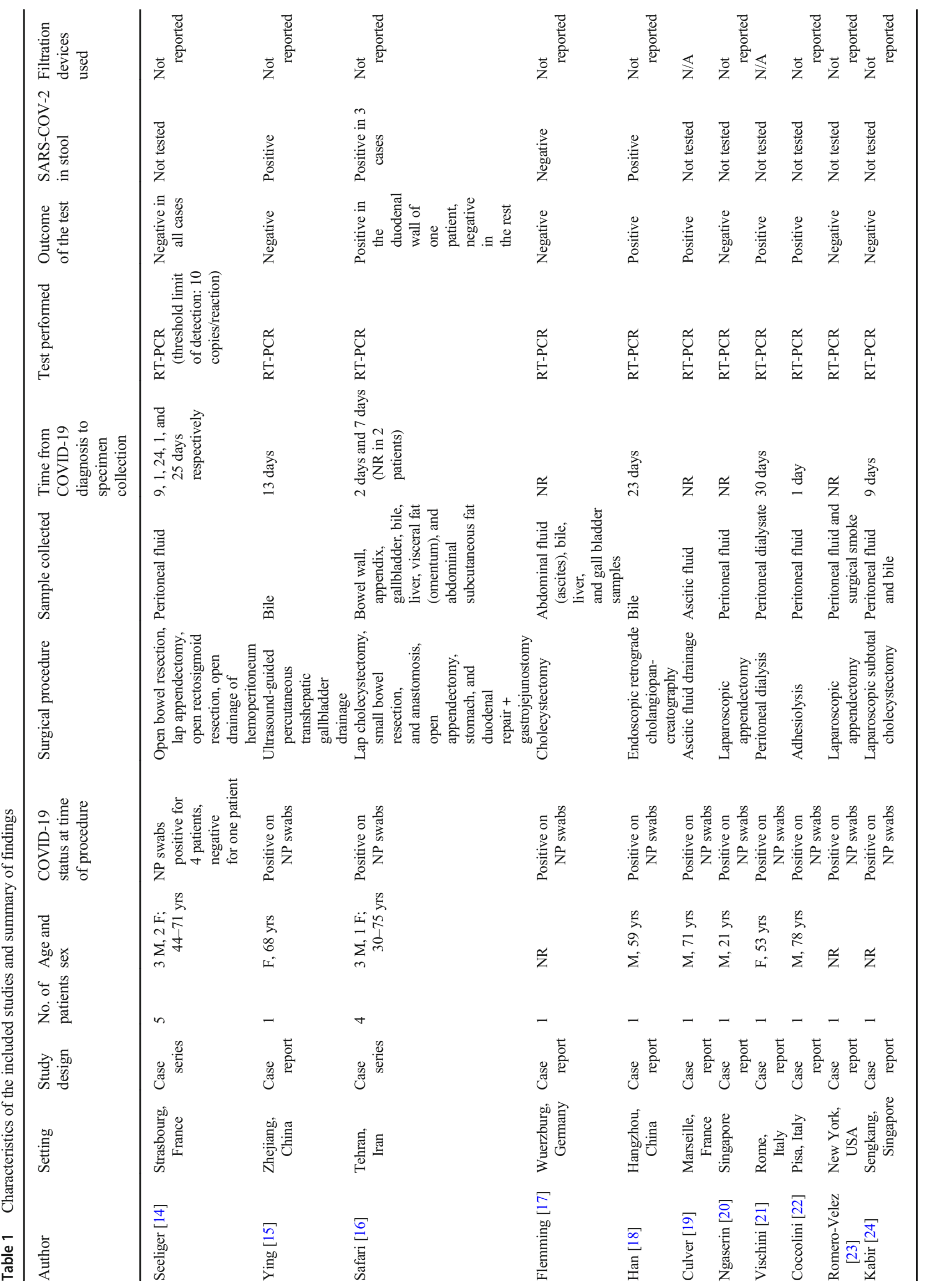




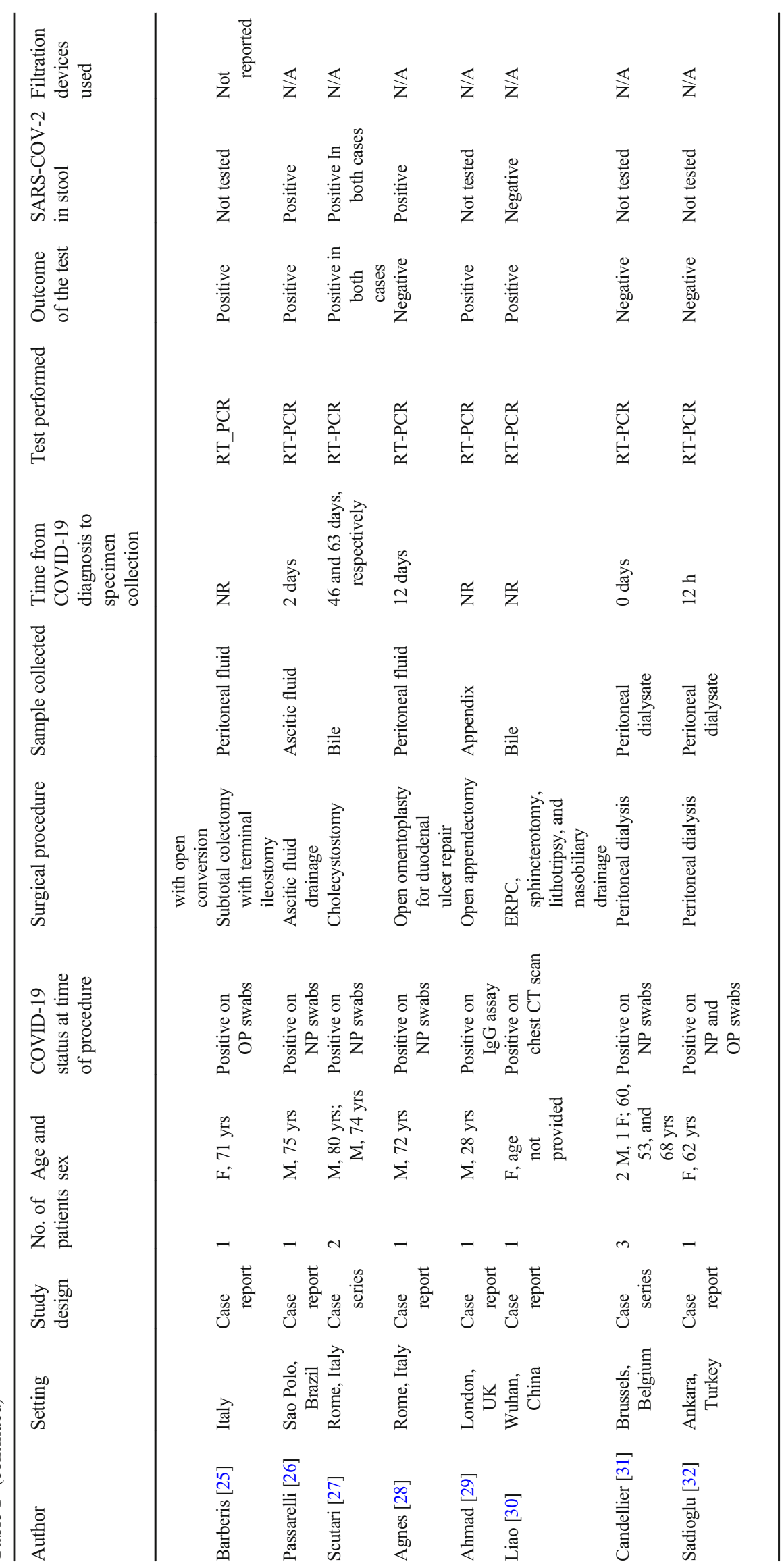


Table 2 Results of SARS-COV2 testing of various tissues across the included studies

\begin{tabular}{llll}
\hline \multirow{2}{*}{ Samples } & & \multicolumn{2}{l}{ Study } \\
\cline { 3 - 3 } & & Positive & Negative \\
\hline Abdominal tissues & Small bowel & $(16)$ & N/A \\
& Appendix & $(29)$ & $(16)$ \\
& Gallbladder/liver & N/A & $(16,17)$ \\
& Omentum & N/A & $(16)$ \\
Abdominal fluids & Bile & $(18,28,31)$ & $(15,16,17$ \\
& Peritoneal fluid & $(22,25)$ & $(14,17,20,23,24,30)$ \\
& Peritoneal dialysate & $(21)$ & $(26,27)$ \\
Surgical smoke & Ascitic fluid & $(19,32)$ & N/A \\
\hline
\end{tabular}

fluid of a 78-year-old patient undergoing adhesiolysis for small bowel obstruction. In the fourth study by Vischini et al. [21], the virus was identified in peritoneal dialysate of end-stage renal disease of a patient undergoing peritoneal dialysis. The fifth study by Barberis [25] successfully detected the viral RNA in the peritoneal fluid of a 71-year-old undergoing subtotal colectomy with terminal ileostomy. In the other 2 studies, SARS-COV-2 RNA was positively identified in the bile [30] and ascitic fluid [26] of COVID-19 patients. The remaining 9 studies did not identify SARS-COV-2 RNA in the abdominal tissues (liver and gallbladder) or fluid (bile and peritoneal fluid/dialysate/brushings) of COVID-19 patients $[14,15,17,20,23,24,28,31,32]$.

Out of the 11 patients with positive findings of SARSCOV-2 in abdominal tissues/fluids, 9 had corresponding positive nasopharyngeal swabs, while two patients (diagnosed with COVID-19 on the basis of chest CT [30] and IgG assays [29]) had negative nasopharyngeal swabs.

\section{Presence of SARS-COV-2 in surgical smoke generated during abdominal surgery}

We identified only one study investigating the presence of SARS-COV-2 RNA in surgical smoke generated during abdominal surgical procedures [23]. Romero-Velez and colleagues [23] collected surgical smoke during laparoscopic appendectomy on a COVID-19 patient. The virus was however not identified within the smoke using real-time RT-PCR.

\section{Discussion}

The COVID-19 pandemic has had a significant impact on the delivery of surgical services to patients worldwide. Guidelines from surgical societies recommended postponement of elective surgical procedures $[1,33]$. Nonetheless, the need to perform emergency and oncological surgery on both COVID-19 patients and non-COVID-19 patients still remained [17, 24].
As laparoscopic surgery is an established treatment modality in surgery [34, 35], and with the gradual resumption of elective surgeries, the risk of virus transmission through surgical smoke/laparoscopic pneumoperitoneum remains an issue of great concern.

\section{Summary of evidence, strengths, and limitations}

In this systematic review, we found that there exist conflicting results on the presence of SARS-COV-2 RNA in abdominal tissues and fluids. We identified 10 reports in which SARSCOV-2 could be successfully identified in the peritoneal fluid, peritoneal dialysate, bile, ascitic fluid, duodenal wall, and appendix of COVID-19 patients [16, 18, 19, 21, 22, 25-27, 29, 30] (Table 2). Similar samples however tested negative for the virus in another 9 studies. Only one study tested for the presence of the virus in laparoscopic surgical smoke, and it reported negative findings [23].

That being said, these findings should be interpreted with caution due to several reasons. First, all studies included in this review utilized RT-PCR to detect SARS-COV-2 RNA. This technique of testing has been shown to yield "false negative" in up to $40 \%$ of the upper respiratory tract specimens of COVID-19 cases [36]. Therefore, it cannot be ruled out that nucleic acid amplification tests (NAATs) may also miss to accurately identify the virus in some abdominal tissues and fluids due to a number of pre-analytical and analytical issues, as described in details by Lippi and colleagues [37]. Second, as the test does not usually distinguish infectious from noninfectious virus [38], the potential infectivity of the contaminated abdominal samples remains unknown. It is noteworthy that none of the studies attempted to demonstrate the presence of a live virus in the samples through techniques such as viral culture and cytopathic studies, so as to provide stronger evidence of infectivity. Third, the possibility of false-positive cases due to sample contamination was not entirely ruled out in some of the cases included in this review. Contamination of samples may occur through sub-optimal skin preparation or from fecal material, which have been shown to 
contain SARS-COV-2 RNA in up to 54\% of COVID-19 patients, as well as from surgical blood, especially in patients with severe illness who may frequently have viremia [39]. Fourth, the studies that were included in this review were either case reports or small case series, which investigated different samples from patients with different pathologies and undergoing different procedures. As such, this introduces significant heterogeneity in results and compromises on generalization. Future studies should take into consideration the above-mentioned issues so as to provide stronger evidence of intraperitoneal viral contamination and risk of viral transmission via laparoscopic surgical smoke.

Although current evidence does not support the hypothesis that SARS-COV-2 can be aerosolized and transmitted through surgical smoke, practical measures to mitigate any theoretical risk are recommended. These include proper use of personal protective equipment within the operating room, limiting the presence of staff during intubations and induction of anesthesia, safe evacuation of all pneumoperitoneum/surgical smoke using ultrafiltration systems, as well as complete evacuation of pneumoperitoneum prior to specimen extraction or conversion to open surgery $[8,40]$. This is crucial, considering the rising number of new infections in many countries, the risk of nosocomial COVID-19 infection (of up to 15\%) [41], and the current widespread unavailability of COVID-19 vaccines.

This is, to the best of our knowledge, the first systematic analysis of the presence of SARS-COV-2 virus in abdominal tissues, fluids, and laparoscopic surgical smoke. We believe our findings are relevant in the formulation of future guidelines for the management of COVID-19 requiring abdominal surgical interventions, especially at a time when resumption of elective surgical procedures have already begun $[42,43]$.

\section{Conclusions}

There are conflicting results regarding the presence of SARSCOV-2 in abdominal tissues and fluids. No currently available evidence supports the hypothesis that SARS-COV-2 can be aerosolized and transmitted through surgical smoke. Larger studies are urgently needed to corroborate these findings.

Supplementary Information The online version contains supplementary material available at https://doi.org/10.1007/s00423-021-02142-8.

Authors' contributions Study conception and design-IC, Acquisition of data-IC and PS, Analysis and interpretation of data-IC, PS, GL, BMH, $\mathrm{RC}$, and JO, Drafting of manuscript-IC, Critical revision of manuscript-All authors

\section{Declarations}

Conflict of interest The authors declare no competing interests.
Research involving human participants and/or animals This article does not contain any studies with human participants performed by any of the authors.

Informed consent This article does not contain any studies with human participants performed by any of the authors.

\section{References}

1. Society of American Gastroenterological and Endoscopic Surgeons (SAGES), European Association for Endoscopic Surgery (EAES). SAGES and EAES recommendations regarding surgical response to COVID-19 crisis [Internet]. SAGES. 2020 [cited 2020 Jul 25]. Available from: https://www.sages.org/recommendations-surgicalresponse-covid-19/

2. Di Saverio S, Khan M, Pata F, Ietto G, De Simone B, Zani E et al (2020) Laparoscopy at all costs? Not now during COVID-19 outbreak and not for acute care surgery and emergency colorectal surgery: a practical algorithm from a hub tertiary teaching hospital in Northern Lombardy, Italy. J Trauma Acute Care Surg 88(6):715718

3. Angioni S (2020) Laparoscopy in the coronavirus disease 2019 (COVID-19) era. Gynecol Surg [Internet]. [cited 2020 Jul 25];17(1). Available from: https://www.ncbi.nlm.nih.gov/pmc/ articles/PMC7224160/

4. Xu H, Zhong L, Deng J, Peng J, Dan H, Zeng X et al (2020) High expression of ACE2 receptor of 2019-nCoV on the epithelial cells of oral mucosa. Int J Oral Sci 12(1):1-5

5. Wu Y, Guo C, Tang L, Hong Z, Zhou J, Dong X, Yin H, Xiao Q, Tang Y, Qu X, Kuang L, Fang X, Mishra N, Lu J, Shan H, Jiang G, Huang X (2020) Prolonged presence of SARS-CoV-2 viral RNA in faecal samples. Lancet Gastroenterol Hepatol 5(5):434-435

6. Henry BM, de Oliveira MHS, Benoit J, Lippi G (2020) Gastrointestinal symptoms associated with severity of coronavirus disease 2019 (COVID-19): a pooled analysis. Intern Emerg Med

7. Gupta N, Agrawal H (2020) COVID 19 and laparoscopic surgeons, the Indian scenario - Perspective. Int J Surg Lond Engl 79:165-167

8. Mintz Y, Arezzo A, Boni L, Baldari L, Cassinotti E, Brodie R, Uranues S, Zheng MH, Fingerhut A (2020) The risk of COVID19 transmission by laparoscopic smoke may be lower than for laparotomy: a narrative review. Surg Endosc 34(8):3298-3305

9. Vigneswaran Y, Prachand VN, Posner MC, Matthews JB, Hussain M (2020) What is the appropriate use of laparoscopy over open procedures in the current COVID-19 climate? J Gastrointest Surg. $1-6$

10. Kwak HD, Kim S-H, Seo YS, Song K-J (2016) Detecting hepatitis $\mathrm{B}$ virus in surgical smoke emitted during laparoscopic surgery. Occup Environ Med 73(12):857-863

11. Sawchuk WS, Weber PJ, Lowy DR, Dzubow LM (1989) Infectious papillomavirus in the vapor of warts treated with carbon dioxide laser or electrocoagulation: detection and protection. J Am Acad Dermatol 21(1):41-49

12. Johnson GK, Robinson WS (1991) Human immunodeficiency virus-1 (HIV-1) in the vapors of surgical power instruments. J Med Virol 33(1):47-50

13. Moher D, Liberati A, Tetzlaff J, Altman DG, PRISMA Group (2009) Preferred reporting items for systematic reviews and metaanalyses: the PRISMA statement. PLoS Med 6(7):e1000097

14. Seeliger B, Philouze G, Benotmane I, Mutter D, Pessaux P (2020) Is the severe acute respiratory syndrome coronavirus 2 (SARS$\mathrm{CoV}-2)$ present intraperitoneally in patients with coronavirus disease 2019 (COVID-19) infection undergoing emergency operations? Surgery. 168(2):220-221 
15. Ying M, Lu B, Pan J, Lu G, Zhou S, Wang D et al (2020) COVID19 with acute cholecystitis: a case report. BMC Infect Dis 20(1):1-4

16. Safari S, Keyvani H, Alamdari NM, Dehghanian A, Hashemi MR, Honar BN, et al. (2020) Abdominal Surgery in Patients with COVID-19: detection of SARS-CoV-2 in abdominal and adipose tissues. Ann Surg [Internet]. [cited 2020 Jul 25];Publish Ahead of Print. Available from: https://journals.lww.com/annalsofsurgery/ Abstract/9000/Abdominal_Surgery_in_Patients_with_COVID_ 19_.94416.aspx

17. Flemming S, Hankir M, Hering I, Meybohm P, Krone M, Weissbrich B, et al. (2020) Abdominal fluid samples (negative for SARS-CoV-2) from a critically unwell patient with respiratory COVID-19. Br J Surg [Internet]. [cited 2020 Jul 25]; Available from: https://www.ncbi.nlm.nih.gov/pmc/articles/PMC7283889/

18. Han D, Fang Q, Wang X SARS-CoV-2 was found in the bile juice from a patient with severe COVID-19. J Med Virol [Internet]. [cited $2020 \mathrm{Jul}$ 25];n/a(n/a). Available from: https://onlinelibrary.wiley. com/doi/abs/10.1002/jmv.26169

19. Culver A, Arbelot C, Bechis C, Cassir N, Leone M (2020) First description of SARS-CoV-2 in ascites. IDCases. 21:e00836

20. Ngaserin SH-N, Koh FH, Ong B-C, Chew M-H (2020) COVID-19 not detected in peritoneal fluid: a case of laparoscopic appendicectomy for acute appendicitis in a COVID-19-infected patient. Langenbeck's Arch Surg 9:1-3

21. Vischini G, D’Alonzo S, Grandaliano G, D'Ascenzo FM (2020) SARS-CoV-2 in the peritoneal waste in a patient treated with peritoneal dialysis. Kidney Int 98(1):237-238

22. Federico C, Dario T, Adolfo P, Cesira G, Mauro P, Marianna L, et al. (2020) SARS-CoV-2 is present in peritoneal fluid in COVID19 patients. In Press

23. Romero-Velez G, Pereira X, Zenilman A, Camacho D (2020) SARS-Cov-2 was not found in the peritoneal fluid of an asymptomatic patient undergoing laparoscopic appendectomy. Surg Laparosc Endosc Percutan Tech [Internet]. [cited 2020 Jul 27];Publish Ahead of Print. Available from: https://journals. lww.com/surgical-laparoscopy/Abstract/9000/SARS_Cov_2_ Was Not Found in the Peritoneal Fluid.99217.aspx

24. Kabir T, Ngaserin S, Koh FH, Huang J, Ong BC, Chew MH. The COVID-19 conundrum: SARS-CoV-2 is not present in bile. BJS Br J Surg [Internet]. [cited $2020 \mathrm{Jul}$ 25];n/a(n/a). Available from: https://bjssjournals.onlinelibrary.wiley.com/doi/abs/10.1002/bjs. 11820

25. Barberis A, Rutigliani M, Belli F, Ciferri E, Mori M, Filauro M. SARS-Cov-2 in peritoneal fluid: an important finding in the Covid19 pandemic. BJS Br J Surg [Internet]. [cited 2020 Aug 16];n/ a(n/a). Available from: https://bjssjournals.onlinelibrary.wiley. com/doi/abs/10.1002/bjs.11816

26. Passarelli VC, Perosa AH, de Souza Luna LK, Conte DD, Nascimento OA, Ota-Arakaki J et al (2020) Detected SARSCoV-2 in ascitic fluid followed by cryptococcemia: a case report. Sn Compr Clin Med 8:1-5

27. Scutari R, Piermatteo L, Ciancio Manuelli M, Iannetta M, Salpini $\mathrm{R}$, Bertoli A, et al. (2020) Long-term SARS-CoV-2 infection associated with viral dissemination in different body fluids including bile in two patients with acute cholecystitis. Life Basel Switz. 10(11)

28. Agnes A, La Greca A, Tirelli F, Papa V (2020) Duodenal perforation in a SARS-CoV-2-positive patient with negative PCR results for SARS-CoV-2 in the peritoneal fluid. Eur Rev Med Pharmacol Sci 24(23):12516-12521

29. Ahmad S, Ahmed RN, Jani P, Ullah M, Aboulgheit H (2020) SARS-CoV-2 isolation from an appendix. J Surg Case Rep [Internet]. [cited 2020 Nov 3];2020(8). Available from: https:// www.ncbi.nlm.nih.gov/pmc/articles/PMC7444615/
30. Liao Y, Wang B, Wang J, Shu J, Zhou W, Zhang H (2020) SARS$\mathrm{CoV}-2$ in the bile of a patient with COVID-19-associated gallbladder disease. Endoscopy. 52(12):1148-1148

31. Candellier A, Scohy A, Gillet N, Muylkens B, Morelle J, Belkhir L, Coupeau D, Jadoul M, Goffin É (2020) Absence of SARS-CoV-2 in the effluent of peritoneal dialysis patients. Perit Dial Int 40(5): 499-503

32. Sadioglu RE, Aktar M, Gulten E, Eyupoglu S, Karahan ZC, Azap A, Sengul S, Ates K, Kutlay S (2020) Does SARS-CoV-2 reach peritoneal effluent? Perit Dial Int 40(5):520-521

33. Royal College of Surgeons (RCS). Guidance for surgeons working during the COVID-19 pandemic [Internet]. The Surgical Royal Colleges of the United Kingdom and Ireland. [cited 2020 Jul 28]. Available from: https://www.rcseng.ac.uk/coronavirus/jointguidance-for-surgeons-v1/

34. Mandala V, editor. The role of laparoscopy in emergency abdominal surgery [Internet]. Mailand: Springer-Verlag; 2012 [cited 2020 Jul 28]. (Updates in Surgery). Available from: https://www. springer.com/gp/book/9788847023260

35. Feig BW (2005) Role of laparoscopy in gastrointestinal malignancies. In: Ajani JA, Lynch PM, Janjan NA, Curley SA, editors. Gastrointestinal Cancer [Internet]. New York, NY: Springer [cited 2020 Jul 28]. p. 58-66. (M. D. Anderson Cancer Care Series). Available from: https://doi.org/10.1007/0-387-27285-2_5

36. Woloshin S, Patel N, Kesselheim AS (2020) False negative tests for SARS-CoV-2 infection - challenges and implications. N Engl J Med. 0(0):null

37. Lippi G, Simundic A-M, Plebani M (2020) Potential preanalytical and analytical vulnerabilities in the laboratory diagnosis of coronavirus disease 2019 (COVID-19). Clin Chem Lab Med 58(7):10701076

38. Atkinson B, Petersen E (2020) SARS-CoV-2 shedding and infectivity. Lancet Lond Engl 395(10233):1339-1340

39. Andersson M, Carcamo CVA, Auckland K, Baillie JK, Barnes E, Beneke T, et al. (2020) SARS-CoV-2 RNA detected in blood samples from patients with COVID-19 is not associated with infectious virus. medRxiv. 2020.05.21.20105486

40. El Boghdady M, Ewalds-Kvist BM (2020) Laparoscopic surgery and the debate on its safety during COVID-19 pandemic: a systematic review of recommendations. The Surgeon [Internet]. [cited 2021 Feb 11]; Available from: https:/www.ncbi.nlm.nih.gov/ pmc/articles/PMC7418789/

41. Carter B, Collins JT, Barlow-Pay F, Rickard F, Bruce E, Verduri A, Quinn TJ, Mitchell E, Price A, Vilches-Moraga A, Stechman MJ, Short R, Einarsson A, Braude P, Moug S, Myint PK, Hewitt J, Pearce L, McCarthy K, Davey C, Jones S, Lunstone K, Cavenagh A, Silver C, Telford T, Simmons R, Holloway M, Hesford J, el Jichi Mutasem T, Singh S, Paxton D, Harris W, Galbraith N, Bhatti E, Edwards J, Duffy S, Kelly J, Murphy C, Bisset C, Alexander R, Garcia M, Sangani S, Kneen T, Lee T, McGovern A, Guaraldi G, Clini E (2020) Nosocomial COVID-19 infection: examining the risk of mortality. The COPE-Nosocomial Study (COVID in Older PEople). J Hosp Infect 106(2):376-384

42. American College of Surgeons. Local resumption of elective surgery guidance [Internet]. American College of Surgeons. [cited $2020 \mathrm{Jul}$ 28]. Available from: https://www.facs.org/covid-19/ clinical-guidance/resuming-elective-surgery

43. Royal College of Surgeons (RCS). Recovery of surgical services during and after COVID-19 [Internet]. Royal College of Surgeons. [cited $2020 \mathrm{Jul}$ 28]. Available from: https://www.rcseng.ac.uk/ coronavirus/recovery-of-surgical-services/

Publisher's note Springer Nature remains neutral with regard to jurisdictional claims in published maps and institutional affiliations. 